DOI 10.37882/2500-3682.2020.12.01

\title{
ЯЗЫК КАК ОНТОЛОГИЧЕСКОЕ ОСНОВАНИЕ И СИСТЕМООБРАЗУЮЩИЙ ЭЛЕМЕНТ КУЛЬТУРЫ
}

\section{LANGUAGE AS AN ONTOLOGICAL FOUNDATION AND A SYSTEM-FORMING ELEMENT OF CULTURE}

E. Agafonov

Summary: In the article, based on the synthesis of modern ideas of cultural studies, cognitive linguistics and non-classical epistemology, an attempt is made to comprehensively analyze the language as the foundation of culture. The systematic meaning of language in relation to such elements of culture as values, norms, traditions is shown. The author analyzes language not only as a specific means of human cognition of the surrounding world, but also as a form of expression of ethnic, social characteristics of culture. The influence of language on various types of human activity is considered as the reason for the actualization of linguistic problems in modern philosophy, which today claims the role of a general methodology of humanitarian knowledge.

Keywords: language, culture, being, man, cognition, meaning, sign, system, element, norms, traditions, values, subculture, sociolect.

\author{
Агафонов Евгений Александрович \\ К.ф.н., доцент, Вологодский институт права \\ и экономики ФСИН России \\ evgenagafonov@inbox.ru
}

Аннотация: В статье на основе синтеза современных идей культурологи, когнитивной лингвистики и неклассической эпистемологии дана попытка комплексного анализа языка как основания культуры. Показано системообразующее значение языка по отношению к таким элементам культуры, как ценности, нормы, традиции. Автор анализирует язык не только как специфическое средство познания человеком окружающего мира, но и как форму выражения этнических, социальных особенностей культуры. Влияние языка на различные виды деятельности людей рассматривается как причина актуализации в современной философии языковой проблематики, которая претендует сегодня на роль всеобщей методологии гуманитарного познания.

Ключевые слова: язык, культура, бытие, человек, познание, смысл, знак, система, элемент, нормы, традиции, ценности, субкультура, социолект.

ального взаимодействия. Но, несомненно, сущностным, фундаментальным среди них является язык, определяющий специфику бытия человека в мире.

Язык - это естественная знаковая система, которая служит орудием выражения мыслей и чувств людей, является важнейшим специфическим средством познания мира и человеческого общения. Абстрактно-логическое мышление, переход к которому в процессе познания осуществляется уже на уровне представления, невозможно без языка, т.к. понятия выражаются с помощью слов. Поэтому, еще Аристотель подчеркивал, что главное отличие человека от животного - это наличие речи [2, с. 466]. Так, животные имеют голос, с помощью которого выражают чувства, могут оперировать предметами для достижения цели, механически запоминать отдельные слова, но не способны обобщать и абстрагировать. Им не доступны такие отвлеченные понятия как «добро», «зло», «жизнь», «смерть». Таким образом, язык необходимо рассматривать как начало и основу человеческой культуры.

Развивая идеи античной классики, М. Хайдеггер утверждает, что наличие языка не есть одна из многих, рядовых способностей людей. «Дар речи отличает человека, только и делая его человеком» [3, с. 259]. В языке раскрывается сущность человека, бытие которого 
возможно «прежде всего в языке и при языке» [там же]. По мнению мыслителя, ошибочно считать, что язык соответствует сущности человека, которого традиционно рассматривают как «рациональное животное», триединство тела, души и духа. Подобное телесно-духовное истолкование затем распространяют и на определение языка, находя в звуках и письме «телесность» слова, «в мелодии и ритме - душу, в семантике - дух языка» [4, с. 203]. Такой подход скрывает бытийно-историческое существо языка.

С точки зрения экзистенциальной антропологии, существо языка необходимо определять через его соответствие бытию, как некое онтологическое вместилище, «жилище» человека. Животные и растения ограничены окружающей средой, не выходят за пределы органики, т. к. не имеют языка. Людям дан иной род бытия - экзистенция, которая является не просто возможностью разума, а есть источник их самоопределения, осмысления сущего с помощью языка.

При этом язык не становится средством господства живого существа, организма над сущим. Язык, напротив, «есть осуществляемый бытием и пронизанный его складом дом бытия» [там же], существуя в котором человек открывает и хранит истину самого бытия. По М. Хайдеггеру, человек не создатель и господин, а «пастух», «сосед» бытия, субъективной задачей которого становится явить сущее, не конструировать новые смыслы, а вернутся к испытующему вопрошанию, «чтобы истина бытия нашла себя в слове и чтобы мысль дала ей это слово» [4, с. 209]. Содержащиеся в языке понятия (концепты, идеи) упорядочивают опыт людей, становятся объективной, внеличностной, онтологической основой познания человеком окружающего мира.

Таким образом, понятия «человек», «общество», «культура» и «язык» во многом тождественны, нераздельны. Можно сказать, что, так или иначе, все эти явления возникают одновременно, одно из них не может существовать без другого. Так, мы знаем, что в природе деятельность животных основана на инстинкте и естественном отборе. Это частично сохраняется и в человеке на уровне индивидуальной психики, в бессознательном. Но общество в целом тем и отличается от животного стада, что в нем доминируют основанные на абстрактно-логическом, понятийном мышлении культурные нормы и ценности, без регулирующей силы которых невозможно взаимодействие между людьми.

Так, мы все хотим, чтобы другие люди поступали с нами честно и справедливо. Можно утверждать, что общечеловеческие, проверенные тысячелетиями нравственные нормы, существующие вне зависимости от сиюминутных стремлений и потребностей индивидов, и есть сущность, истинное содержание бытия, которое, по утверждению М. Хайдеггера, призван раскрыть человек с помощью языка. Отталкиваясь от начального значения слова, философ трактует этику как осмысление бытия, местопребывания человека. Субъект не рассматривается им как средоточие сущего, а необходимость нормирования и всеобщая этика становятся результатом потерянности, заброшенности человека. Бытие дает правила и законы как предназначения, раскрывающие его миссию, способные поддерживать и обязывать. Только истина бытия определяет уместность поведения, иначе «всякий закон остается просто подделкой человеческого разума» [4, с. 218], мысль посредством слова выражает смысл бытия.

Таким образом, язык, прежде всего, выполняет гносеологическую функцию: является специфическим средством освоения человеком мира, концентрирует, накапливает и закрепляет в устной и письменной форме социальный опыт множества людей, формирует систему знаний о мире. Являясь важнейшим средством человеческой коммуникации, язык реализует возможность культурного взаимодействия, обмена информацией. Но как системообразующее ядро культуры язык связан и с другими ее элементами. Так, язык историчен и сберегает бытие в памяти людей. Без него невозможна передача накопленного культурой социального опыта, существующая в форме обычаев и традиций. Усвоение индивидом знаний и ценностей, приобщение к социальным ролям и нормативному поведению, формирование личности человека, как было показано выше, также происходит только на основе языка, который дает бытию слово.

Язык есть явление социальное, приобщение к нему возможно только в рамках общественного взаимодействия. Известно, что ребенок, выросший в лесу, среди зверей, имея физиологические предпосылки к развитию речи, сам языка не освоит. Через язык человек впитывает сущность и своеобразие родной культуры, утверждает свою связь с ней. При этом язык отражает психические особенности, ментальность конкретного народа, которая сформировалась через опыт жизни в определенных природных условиях.

С этнической точки зрения, культуру можно рассматривать как способ групповой адаптации, своеобразный механизм выживания социальной общности. Представители «различных культур структурируют мир вокруг себя по-разному, по крайней мере в языке, который они используют для описания этого мира» [5, с. 264]. Язык как сложная система отражает эти особенности восприятия реальности на лексическом, грамматическом, синтаксическом и даже фонетическом уровнях. Например, эквивалентные слова отдельных языков могут нести разные оттенки смысла, иметь подтексты, сопутствующие значения и ассоциации, использовать в разном контексте. В зависимости от значимости смысла, одно явление в 
национальных языках может обозначаться разным количеством слов. Языковые различия между культурами проявляются также в использовании местоимений и числительных, специфике организации грамматической структуры предложения.

Известно, что даже в рамках одного языка существуют диалекты, имеющие, зачастую, не только своеобразную лексику, но и особый фонетический строй речи. Ярким примером тому является различие типов безударного вокализма русских говоров. Так, характерной чертой северного наречия стало «оканье» - «протягивание», проговаривание звука «о» в неударных слогах. Истоком этого, несомненно, стал неспешный, размеренный уклад жизни земледельца в условиях северной природы, где большую часть года лежит снег.

Местные диалекты и говоры как варианты географических разновидностей языка активно изучались лингвистами уже в XIX-XX веках. Сегодня особый интерес представляет социолингвистика, возникшая на стыке языкознания, социологии и культурологии, выделяющая в общенациональном языке особые, групповые разновидности. Эти социальные языки, коренной причиной появления которых является общественное разделение труда, Р. Барт предлагает именовать «социолектами». Мыслитель призывает отказаться от эмпирического взгляда на лингвистический материал и рассматривать разделение языков как «всеохватывающее явление, затрагивающее самые основы нашего экономического строя, культуры, быта, даже истории» [6, с. 525].

Напомним, что одним из актуальных терминов современной социологии культуры является понятие «субкультура», отражающее особый способ жизнедеятельности отдельных социальных групп в обществе. Стремясь к обособлению, каждая субкультура воспроизводит общую модель морфологии культуры, имеет свой «язык», нормы, ценности, обычаи и традиции. Наличие субкультур помогает человеку приспособиться к сложности, раздробленности современного общества, и разделение языков играет в этом не последнюю роль.

Так, в советском языкознании термин «жаргон» использовался «для обозначения явлений дифференциации языка, которые имеют узкую социальную базу» [7, с. 129], возникают на основе единства профессии, интересов, увлечений, возраста или положения в обществе. Жаргон, таким образом, рассматривался как речевой феномен, используемый для вербального обособления социальной группы от базовой части языковой общности.

В современной социолингвистике на основе поведенческого подхода и анализа актуальных видов общественной активности индивидов выделяют все новые разновидности социальных диалектов: политический, биржевой, компьютерный, рекламный, автомобильный жаргоны. Подобные социолекты раскрывают культуру во всей полноте ее общественного бытия, становятся для современного человека вербальными ориентирами выбора ценностных приоритетов и форм деятельности. Поэтому когнитивная лингвистика и лингвокультурология, отказываясь от поверхностного, описательного взгляда, рассматривают языковые единицы как своеобразные культурные коды, определяющие способы презентации концептуальных смыслов [8, с. 152]. Конечной целью подобных исследований является не просто реконструкция языковой «картины мира», но выявление специфики его восприятия и способов жизнедеятельности индивида, социальной группы или общества в целом на определенном этапе развития.

По справедливому утверждению Б. Уорфа, необходимо «признать влияние языка на различные виды деятельности людей не столько в особых случаях употребления языка, сколько в его постоянно действующих общих законах и в повседневной оценке им тех или иных явлений» [9, с. 158]. Неслучайно в современной философии языковая проблематика, становясь одной из ведущих тем, занимает место мышления, «пустого» cogito. Неклассическая традиция «развертывается в ситуации погруженности в культуру» [10, с. 143], акцентирует внимание на маргинальном, нерефлективном, непредъявленном сознанию содержании. Архетипы, желания, воля, обыденное, полисемичное и метафоричное, отражающие фрагментарный опыт культуры, артикулируются в амбивалентности языка, который одновременно обнаруживает и скрывает смыслы, разъединяет и связывает людей. Можно сказать, что сегодня философия языка выросла до всеобщей методологии гуманитарного познания и во многом определяет специфику современных подходов к пониманию сущности человека, общества и культуры.

\section{ЛИТЕРАТУРА}

1. Бачинин В.А. Культура // Бачинин В.А. Культурология. Энциклопедический словарь. СПб. Изд-во Михайлова В.А., 2005. С. 127-129.

2. Аристотель. Политика. // Антология мировой философии. В 4-х томах. Т. 1. Философия древности и средневековья. Ч. 1. М.: Мысль, 1969. С. 465-475.

3. Хайдеггер М. Путь к языку // Хайдеггер М. Время и бытие: Статьи и выступления. М.: Республика, 1993. 259-273 с.

4. Хайдеггер М. Письмо о гуманизме // Хайдеггер М. Время и бытие: Статьи и выступления. М.: Республика, 1993 . С $192-220$.

5. Мацумото Д. Психология и культура. СПб.: прайм-ЕВРОЗНАК, 2002. 416 с. 
6. Барт Р. Разделение языков. // Барт Р. Избранные работы: Семиотика: Поэтика: Пер. с фр. / Сост., общ. ред. и вступ. ст. Г. К. Косикова. М.: Прогресс, 1989. C. 519-534.

7. Руденко М.Ю. Исследование арго, жаргона и сленга: вопросы терминологии // Филологические науки. Вопросы теории и практики, 2016. № 5(59): в 3-х ч. 4. 3. С. 127-134.

8. Хомяков Е.А. Коды культуры в жаргонной фразеологии // Известия высших учебных заведений. Поволжский регион. Гуманитарные науки. 2014. № 3 (31). С. 151-160.

9. Уорф Б.Л. Отношение норм поведения и мышления к языку // Языки как образ мира. М.: 000 «Издательство АСТ»; СПб.: Terra Fantastica, 2003. С. 157-201.

10. Автономова Н.С. Перевод как рефлексивный ресурс понимания // Человек: Образ и сущность. Гуманитарные аспекты. 2009. № 1. С. 139-162.

(с) Агафонов Евгений Александрович (evgenagafonov@inbox.ru).

Журнал «Современная наука: актуальные проблемы теории и практики»

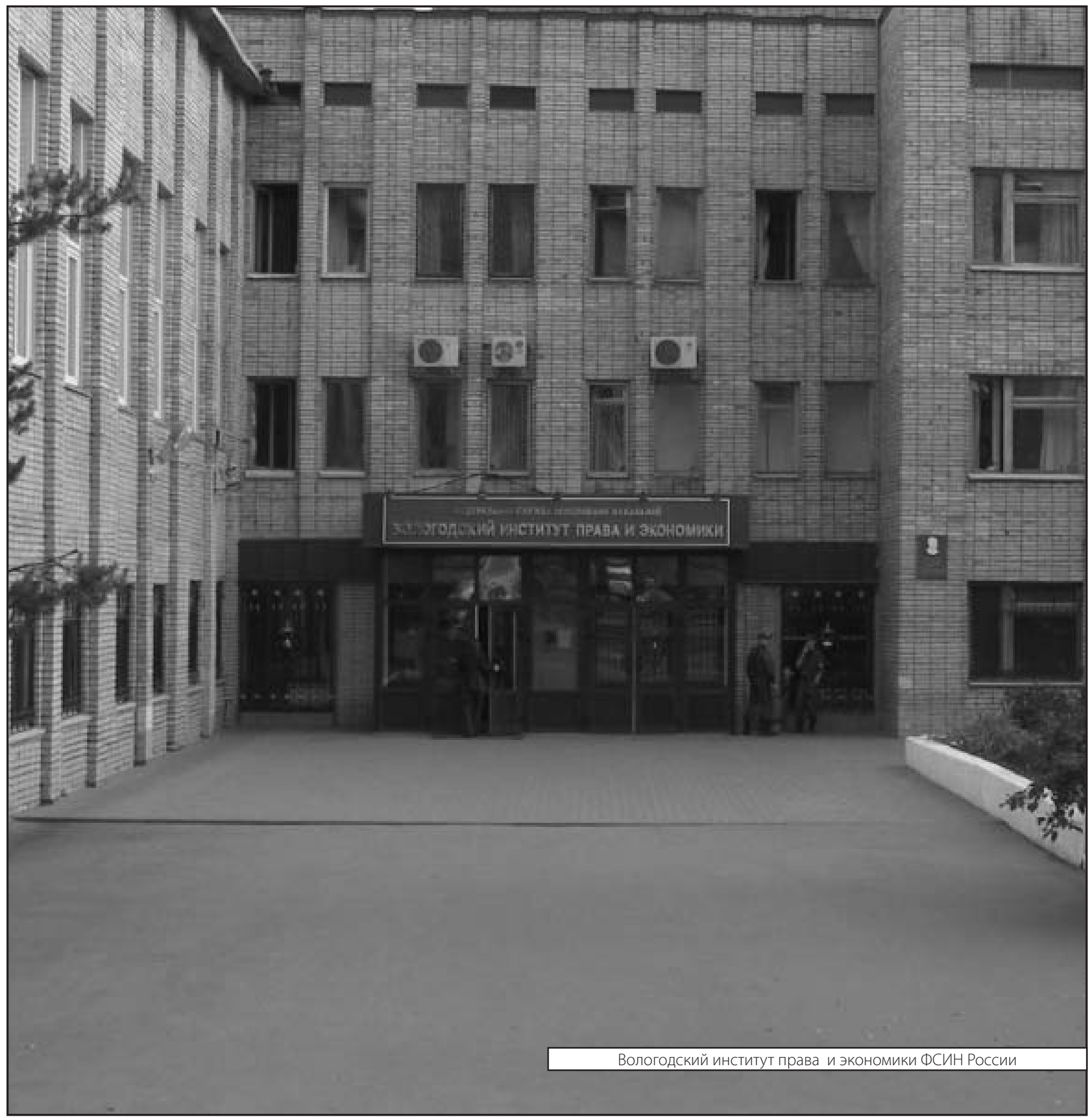

